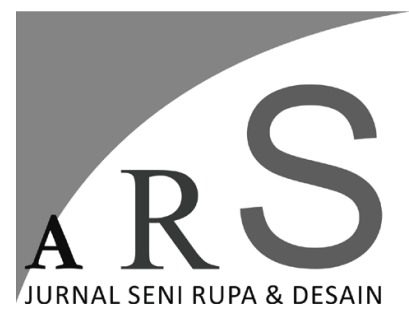

Volume 23 Nomor 2 Mei - Agustus 2020

\section{KAJIAN PERKEMBANGAN DESAIN, WARNA DAN NILAI MOTIF KEMBANG KOPI PADA BATIK TULIS di BANGKALAN MADURA, TAHUN 2005-2015}

\author{
Moh. Solihin Kadafi, Warih Handayaningrum \\ Program Studi Pendidikan Seni Budaya \\ Pascasarjana, Universitas Negeri Surabaya \\ E-mail: solihinkadafi@gmail.com
}

\begin{abstract}
ABSTRAK
Batik adalah karya orang Indonesia yang sudah dikenal sejak lama, merupakan hasil perpaduan seni dan teknologi dari nenek moyang yang nilainya sangat tinggi. Batik adalah gambar dari budaya kerajinan tinggi orang Indonesia. Penelitian ini menggunakan deskriptif kualitatif. Data dikumpulkan dengan cara observasi, wawancara dan dokumentasi berupa foto ataupun buku bukuyang relevan berhubungan dengan motif batik. Metode analisis yaitu ada tiga yaitu: 1. Reduksi data, 2. Penyajian data, 3. Keabsahan data. Hasil akhir dari penciptaan kembang kopi yang di stilisasikan menjadi hewan dengan ciri khas warna yang mencolok. Dari penciptaan karya ini diharapkan dapat memberikan kontribusi yang bermanfaat terhadap perkembangan dunia seni kriya terutama tekstil, dan juga dapat menumbuhkan kecintaan masyarakat terhadap batik agar dikenakan dalam berbagai kesempatan.
\end{abstract}

Kata Kunci : kriya tekstil, dan motif kembang kopi

\begin{abstract}
Study Of Development Of Design, Color And Value Of Coffee Development In Write Batik In Bangkalan Madura, 2005-2015. Batik is an Indonesian work that has been known for a long time, is the result of a combination of art and technology from ancestors whose values are very high. Batik is an image of the high craft culture of Indonesia. This research uses descriptive qualitative. Data collected by observation, interviews and documentation in the form of photos or books that are relevant to batik motifs. There are three analytical methods, namely: 1. Data reduction, 2. Presentation of data, 3. Data validity. The end result of the creation of coffee flowers is sterilized into animals with striking color characteristics. From the creation of this work it is hoped that it can make a useful contribution to the development of the world of craft art, especially textiles, and can also foster people's love of batik to be worn on various occasions.
\end{abstract}

Keyword: Kriya Tekstil, and motif coffee flowers. 


\section{Pendahuluan}

UNESCO telah menetapkan sebagai warisan kemanusiaan untuk budaya lisan dan nonbendawi (materpieces of the oral and intangible heritage of humanity) sejak 2 oktober, 2009. Oleh karena itu, sudah sewajarnya saat ini orang Indonesia mulai memperhatikan batik.

Batik adalah hasil karya bangsa Indonesia yang sudah dikenal sejak dahulu, merupakan hasil perpaduan antara seni dan teknologi para leluhur yang sangat tinggi nilainya. Batik merupakan citra ketinggian budaya kriya bangsa Indonesia yang mencirikan kerumitan dan kehalusan ragam hias yang tumbuh melalui goresan canting yang dilukiskan.

Batik merupakan kerajinan yang memiliki nilai seni tinggi dan telah menjadi bagian dari budaya Indonesia. Kita sebagai generasi muda bangsa Indonesia dituntut sadar untuk melestarikan, menjaga, mengembangkan dan mempertahankan apa yang telah kita milik sekaligus mengembangkannya, sehingga mampu bersaing dengan seni dan media-media modern, yang telah mengalihkan perhatian masyarakat dari seni budaya tradisional lokal bangsa Indonesia.

Kata batik berasal dari bahasa Jawa kuno yaitu: yaitu " $B a$ " adalah bo-hobo-hob adalah bayangandan "Tik" adalah tika adalah huruf, tulisan, gambar. Maka kata batik berarti suatu tulisan atau gambaran yang seakan-akan mempunyai bayangan (Wulan, 2011:3).

Batik dalam bahasa Jawa Kromo mengandung arti serat. Serat yang dimaksud adalah seratan atau tulisan, yaitu coretan atau gambar dengan garis yang mempunyai arti tertentu. (Mifzal, 2012:13).

Indonesia memiliki sejarah dan riwayat batik yang panjang di setiap wilayah di Nusantara, batik memiliki perkembangan dan kisah yang menarik. Keberadaan kerajaan Majapahit sebagai kerajaan yang besar, makmur dan mengalami masa kejayaan selama berabad-abad telah membuat tradisi dan kebudayaannya mengakar kuat di wilayah nusantara, termasuk di antaranya ialah batik.

Perkembangan umum sampai saat ini, sebenarnya kapan batik mulai tercipta masih menjadi tanda tanya, namun motif-motif di Indonesia dapat ditemukan pada beberapa artefak budaya, seperti pada candi-candi. Motif dasar Lereng dapat ditemukan pada patung emas Syiwa yang dibuat abad IX di Gemuruh Wonosobo.

Motif ceplok ditemuakan pada pakaian patung Ghanesa di candi Banon dekat candi Borobudur dibuat abad IX. Batik juga ditemukan pada titik-titik dalam motif pada patung Padmipani di Jawa Tengah. Motif liris ditemukan pada patung Manjusri Ngemplak, Semongan, Semarang yang dibuat abad $\mathrm{X}$.

Batik semakin eksis pada masa kerajaan Majapahit dengan wilayah dan kekuasaan sangat luas, namun data yang lebih pasti tentang sejarah dan perkembangan batik di Indonesia mulai terekam jelas sejak masa kerajaan Mataram Islam, yang bersumber dari keraton, seperti motif Parang Rusak, Semen Rama, dan lain-lain.

Pada awalnya batik digunakan sebagai hiasan pada daun lontar yang berisi naskah Indonesia dengan bangsa asing, maka mulai dikenal media batik pada kain. Sejak itu batik mulai digunakan sebagai corak kain yang berkembang sebagai busana tradisional, khusus digunakan di kalangan ningrat keraton.

Beberapa literature, sejarah pembatikan di Indonesia sering dikaitkan dengan kerajaan Majapahit dan penyebaran agama Islam di pula Jawa. Hal ini dibuktikan dengan penemuan arca dalam candi Ngrimbi dekat Jombang yang menggambarkan sosok Raden Wijaya raja pertama Majapahit (memerintah 1294-1309), memakai kain batik bermotif Kawung.

Kesenian batik diyakini telah dikenal sejak zaman kerajaan Majapahit secara turun-temurun. Wilayah kerajaan Majapahit yang sangat luas menyebabkan batik juga dikenal luas di Nusantara.

Sejarah batik Madura sudah ada sejak zaman kerajaan Majapahit, Majapahit singgah di Madura dengan menggunakan pakaian batik yang sangat menawan dan menambah kegagahannya. Kain batik Madura mulai dikenal masyarakat luas pada abad ke 16 dan 17 hal ini bermula ketika terjadi peprangan di Pamekasan Madura antara Raden Azhar melawan Kek Lesap. Raden Azhar merupakan ulama penasihat spritiual Adipati Pamekasan yang bernama Raden Ismail (Adipati Karya Adikara IV), sedangkan Kek Lesap merupakan putera Madura keturunan Cakraningrat I dengan istri selir. 
Dalam peperangan itu Raden Azhar memakai pakaian kebesaran kain batik dengan motif Parang atau dalam Bahasa Madura disebut motif Leres yakni kain batik motif garis melintang simetris. Ketika Raden Azhar memakai batik motif parang kharismanya sangat tinggi dan tampak gagah berwibawa. Sejak itulah batik menjadi perbincangan di kalangan masyarakat Madura.

Perjalanan sejarah batik, batik Madura saat ini boleh dikatakan mencapai kejayaan, apalagi dengan perencaan hari batik nasional tanggal 2 oktober oleh Presiden Susilo Bambang Yudoyono. Para perajin batik di sentra-sentra batik Madura mengalami kegairahan membatik seperti sentra batik tulis Tanjung Bumi di Bangkalan, sentra batik tulis Banyumas Klampar, Pamekasan, dan sentra batik tulis Pekandangan Sumenep.

Kecamatan Tanjung Bumi Bangkalan Madura sudah terkenal hingga ke manca negara dengan batik Gentongan dan batik Kembang Kopi yang menarik dan beda dari yang lain. Motif Kembang Kopi gabungan antara biji kopi dengan kembang sehingga menjadi motif kembang kopi, dengan adanya penggayaan/desain baru batik kembang kopi meningkat dan hanya terdapat di Tanjung Bumi, batik ini sudah mulai langka di Tanjung Bumi dikarenakan sang pengrajinnya mulai bosan dengan desain yang lama sehingga keluar ide-ide baru dari sang pengrajin yaitu desain abstrak.

Perkembangan desain motif Kembang Kopi terinspirasi dari pemuda-pemuda yang sering meminum kopi di malam hari untuk menjaga kampung atau biasanya kalau ada hajatan atau nikahan. Dari situlah pengrajin menciptakan motif Kembang Kopi yang asalnya dari biji kopi dan distilisasikan menjadi kembang kopi, pengrajin tidak berhenti di situ, pengrajin mengeluarkan ide yang kreatif setiap tahunnya untuk mengembangkan desain yang aslinya kembang kopi di kembangkan menjadi betuk hewan tetap dari biji kopi yang distilisasikan menjadi bentuk hewan supaya pembeli atau pengkoleksi batik tidak bosen dengan batik tulis motif kembang kopi tersebut.

\section{Metode Penelitian}

Pendekatan penelitian menggunakan penelitian deskriptif kualitatif, hasil penelitian dilakukan dengan cara memilah-milah, memilih, menganalisis, menyajikan, dan menyimpulkan.

Metode merupakan kegiatan ilmiah yang berkaitan dengan suatu cara kerja (sistematis) untuk memahami suatu subjek atau objek penelitian, sebagai upaya untuk menemukan jawaban yang dapat dipertanggung jawabkan secara ilmiah dan termasuk keabsahannya”.

Teknik pengumpulan data dari penelitian ini yaitu menggunakan cara survey lapangan, wawancara, dan dokumentasi berupa buku-buku sebagai sumber refrensi yang digunakan untuk mendapatkan hasil analisis.

Adapun sumber data yang digunakan dalam pengumpulan informasi tentang apa yang akan dibahas penulis dalam dalam penulisan skripsi ini yaitu melalui pengambilan data primer dan juga data sekunder.

Teknik Analisis Data dibagi menjadi 3 yaitu 1. Reduksi data, 2. Penyajian data, 3. Keabsahan data. Reduksi data ini dilakukan guna memilah data-data yang di dapat pada saat dilapangan. Data yang didapat dilapangan sangat banyak, sehingga data tersebut harus dipilih agar proses penganalisaan lebih fokus ke satu titik. Peniliti mengambil pokok-pokok dari berapa data tentang motif kembang kopi dari tahun 20052015. Secara umum, dalam penilitian kualitatif untuk menyajikan data adalah dengan teks yang bersifat naratif. Penelitian ini setelah mereduksi data peniliti melakukan penyajian data dalam bentuk narasi untuk mempermudah tahap serta memahami hasil penilitian (Sugiyono, 2010:29). Dalam penelitian ini untuk mengurangi kesalahan dalam penelitian. Peneliti melakukan teknik wawancara langsung dari lapangan, dan informasi dari sumber lain yang sama. Sehingga bisa dipertanggung jawabkan keaslian dari datadata yang diperoleh.

\section{Pembahasan Hasil Temuan}

Suriyah lahir di Tanjung Bumi dan di besarkan di Tanjung Bumi, Suriyah sudah dari SMA sudah bergelut di bidang batik karena keluarganya banyak yang bergelut dibidang batik. Suriyah sudah banyak membuat motifmotif batik khas Tanjung Bumi salah satunya ialah motif Kembang Kopi.

Suriyah mulai membuat batik motif Kembang Kopi asal mulanya warga-warga Tanjung Bumi sering meminum kopi hampir 
setiap harinya dari itulah suriyah menciptakan motif Kembang Kopi. Ide penciptaan desain motif kembang kopi tersebut dikarenakan kebiassaan warga meminum kopi dan itulah yang dibuat karya seni yaitu berupa batik dan bermotif Kembang Kopi. Meningkatkan daya kreativitas pencipta maupun pengrajinnya sendiri. Hal ini seperti yang diungkapkan oleh Suriyah dalam bahasa Madura:

deiyeh dek Apah pole mon bedeh akadik moremoan merammeh paleng benyak kopi esedia agih biasanah ebereng aghi bik kacang mareh tambah nyaman ben sopan, deddih kopi nekah bik reng tanjung bumeh setiap malem akadik kancah polanah selalu bedeh e penggir gebey mareh lok ngantok mon malem gebey ge jege takok bedeh pa apah e lingkungan, kopi emedureh benyak artenah.

Artinya : Apa lagi kalau ada acara hajatan minumannya kopi, kopi dan kopi karena sudah diturunkan dari generasi ke generasi sehingga kopi seperti teman yang selalu hadir didekatnya dan juga kopi teman begadang karena kopi tidak membuat ngantuk.

Batik tulis motif Kembang Kopi sebagai ikon rumah industri bu Suriyah di desa Macajah Tanjung Bumi. Ikon adalah tanda yang antara tanda dengan acuannya ada hubungan kemiripan dan biasa disebut metafora. Contoh ikon ialah potret. (Tinarbuko, 2008:14)

Perkembangan Motif Kembang Kopi dari Tahun 2005-2015 :

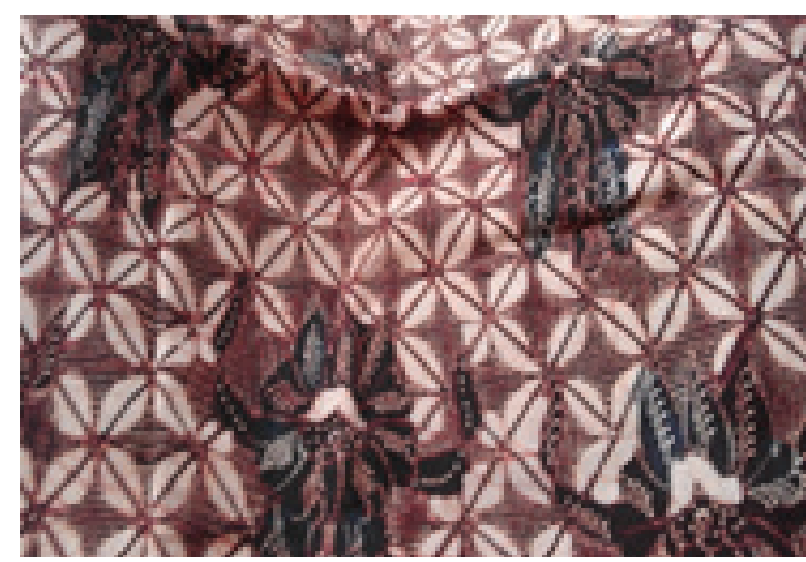

Gambar 1.

Motif Kembang Kopi Tahun 2000

(Sumber : Suriyah di desa Macajah)

Batik tulis motif asli kembang kopi pertama kali yang dibuat oleh suriyah bertempat di tanjung bumi bangkalan Madura. batik tersebut sangat lama dan baru ada perkembangan sejak tahun 2005 - 2015 itupun ada 6 buah batik.

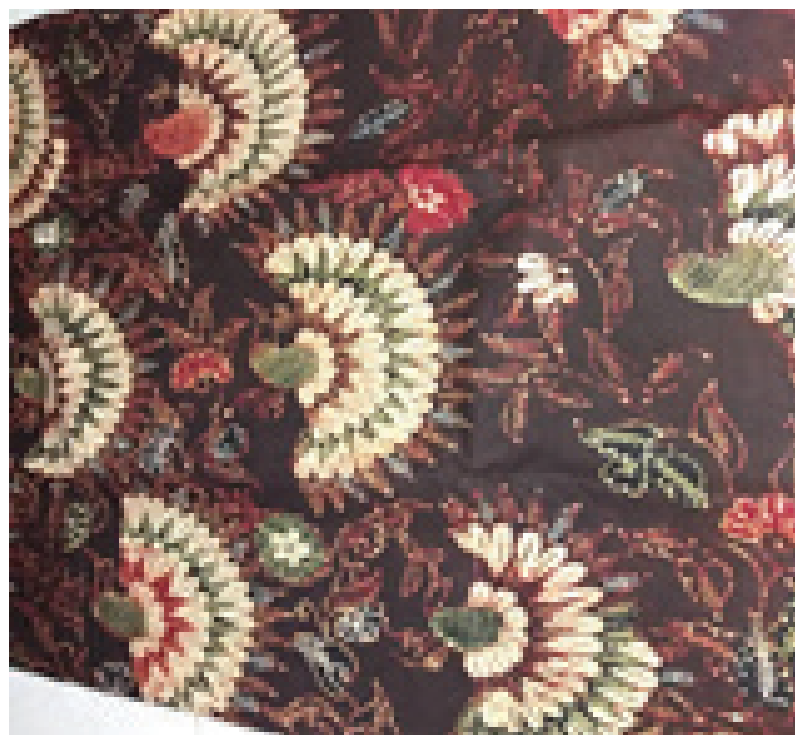

Gambar 2.

Motif Kembang Kopi Tahun 2005

(Sumber : Suriyah di desa Macajah)

Motif Kembang Kopi memiliki prinsip stilisasi atau penggayaan menjadi burung merak dari biji kopi dan kembang, berupa garis lengkung memiliki tekstur nyata berupa kembang. Warna yang terdapat di batik tersebut ialah merah tua, kuning, hijau, merah dan hitam.

Ada beberapa Nilai-nilai yang terkandung dalam motif tersebut ialah :

1. Nilai seni

Bervariasi, baik dari bahan, proses pembuatannya, maupun motifnya yang sekarang berkemban dengan pesat dan banyak diproduksi. Batik motif kembang kopi digunakan sebagai pakaian harian, pakaian resmi, dan pakaian seragam.

2. Nilai budaya

Batik tulis motif kembang kopi ialah perpaduan antara kembang dan biji kopi yang mengahsilkan motif kembang kopi dengan menggunakan stilisasikan menjadi sebuah seni yang indah selain indah juga menghasilkan sebuah karya seni yang bermanfaat ialah sebagai penutup raga.

3. Nilai ekonomis

Pengrajin batik mendapat imbalan yang dapat digunakan untuk memenuhi kebutuhan hidupnya. Dimana keberadaan batik di kampong tersebut memberikan 
lapagan pekerjaan bagi para pengrajin untuk memenuhi banyaknya pesanan pasar dikarenakan sebgai bentuk eksistensi batik itu sendiri sehingga motif tidak tertinggal dengan motif-motif yang lainnya.

4. Nilai pendidikan dan filosofis

Upaya nilai pendidikan dan filosif khususnya pada batik tulis Tanjung Bumi dengan membawa batik tersebut ke sekolah baik dalam bentuk pelajaran intrakulikuler ataupun ekstrakulikuler. Dengan usaha tersebut agara generasi muda khususnya pelajar menjadi mengenal batik secara lebih mendalam. Pelajar juga diusahakan untuk bisa membuat batik tulis Tanjung Bumi supaya ikut melestarikan budaya batik yang berada di Tanjung Bumi, Bangkalan Madura Jawa Timur.

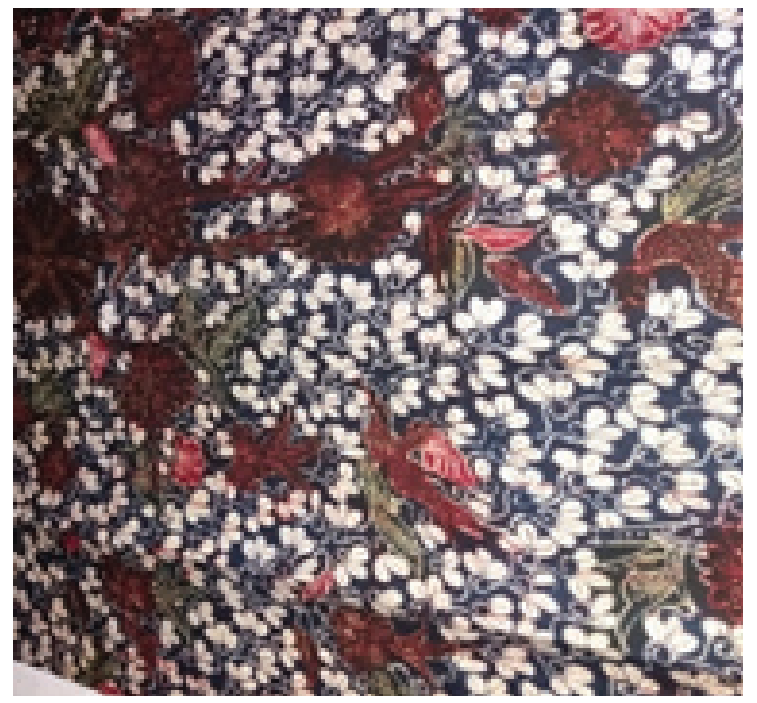

Gambar 3

Motif Kembang Kopi Tahun 2008

(Sumber : Suriyah di desa Macajah)

Ada beberapa Nilai-nilai yang terkandung dalam motif tersebut ialah :

1. Nilai seni

Bervariasi, baik dari bahan, proses pembuatannya, maupun motifnya yang sekarang berkemban dengan pesat dan banyak diproduksi. Batik motif kembang kopi digunakan sebagai pakaian harian, pakaian resmi, dan pakaian seragam.

2. Nilai budaya

Batik tulis motif Kembang Kopi ialah perpaduan antara kembang dan biji kopi yang mengahsilkan motif Kembang Kopi dengan menggunakan stilisasikan menjadi sebuah seni yang indah selain indah juga menghasilkan sebuah karya seni yang bermanfaat ialah sebagai penutup raga.

3. Nilai ekonomis

Pengrajin batik mendapat imbalan yang dapat digunakan untuk memenuhi kebutuhan hidupnya. Dimana keberadaan batik di kampong tersebut memberikan lapagan pekerjaan bagi para pengrajin untuk memenuhi banyaknya pesanan pasar dikarenakan sebgai bentuk eksistensi batik itu sendiri sehingga motif tidak tertinggal dengan motif-motif yang lainnya.

4. Nilai pendidikan dan filosofis

Upaya nilai pendidikan dan filosif khususnya pada batik tulis Tanjung Bumi dengan membawa batik tersebut ke sekolah baik dalam bentuk pelajaran intrakulikuler ataupun ekstrakulikuler. Dengan usaha tersebut agara generasi muda khususnya pelajar menjadi mengenal batik secara lebih mendalam. Pelajar juga diusahakan untuk bisa membuat batik tulis Tanjung Bumi supaya ikut melestarikan budaya batik yang berada di Tanjung Bumi, Bangkalan Madura Jawa Timur

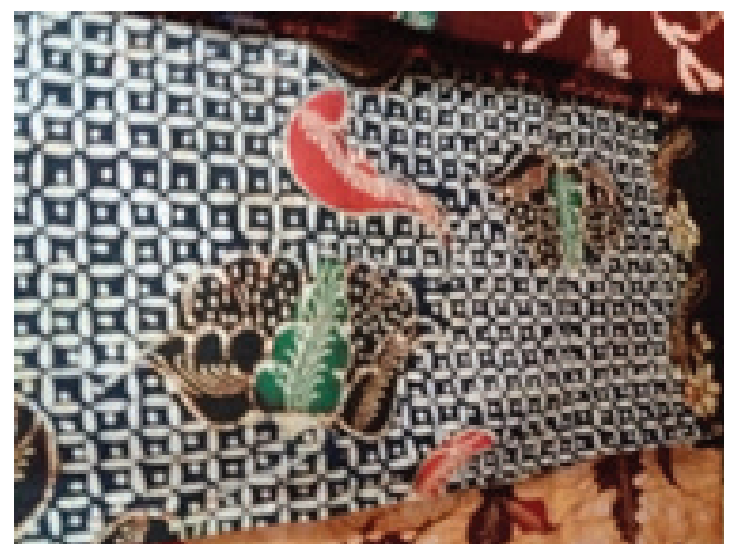

Gambar 4

Motif Kembang Kopi Tahun 2009

(Sumber : Suriyah di desa Macajah)

Ada beberapa Nilai-nilai yang terkandung dalam motif tersebut ialah :

1. Nilai seni

Bervariasi, baik dari bahan, proses pembuatannya, maupun motifnya yang sekarang berkemban dengan pesat dan banyak diproduksi. Batik motif kembang kopi 
digunakan sebagai pakaian harian, pakaian resmi, dan pakaian seragam.

2. Nilai Budaya

Batik tulis motif Kembang Kopi ialah perpaduan antara kembang dan biji kopi yang mengahsilkan motif kembang kopi dengan menggunakan stilisasikan menjadi sebuah seni yang indah selain indah juga menghasilkan sebuah karya seni yang bermanfaat ialah sebagai penutup raga.

3. Nilai ekonomis

Pengrajin batik mendapat imbalan yang dapat digunakan untuk memenuhi kebutuhan hidupnya. Dimana keberadaan batik di kampong Tanjung Bumi memberikan lapagan pekerjaan bagi para pengrajin untuk memenuhi banyaknya pesanan pasar dikarenakan sebgai bentuk eksistensi batik itu sendiri sehingga motif tidak tertinggal dengan motif-motif yang lainnya.

4. Nilai pendidikan dan filosofis

Upaya nilai pendidikan dan filosif khususnya pada batik tulis Tanjung Bumi dengan membawa batik tersebut ke sekolah baik dalam bentuk pelajaran intrakulikuler ataupun ekstrakulikuler. Dengan usaha tersebut agara generasi muda khususnya pelajar menjadi mengenal batik secara lebih mendalam. Pelajar juga diusahakan untuk bisa membuat batik tulis Tanjung Bumi supaya ikut melestarikan budaya batik yang berada di Tanjung Bumi, Bangkalan Madura Jawa Timur.

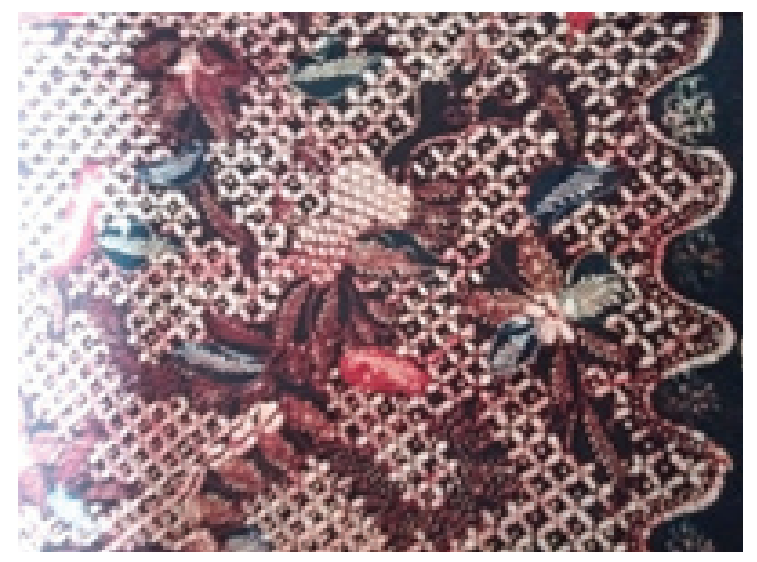

Gambar 5.

Motif Kembang Kopi Tahun 2012

(Sumber : Suriyah di desa Macajah)

Ada beberapa Nilai-nilai yang terkandung dalam motif tersebut ialah :

1. Nilai seni

Bervariasi, baik dari bahan, proses pembuatannya, maupun motifnya yang sekarang berkemban dengan pesat dan banyak diproduksi. Batik motif kembang kopi digunakan sebagai pakaian harian, pakaian resmi, dan pakaian seragam.

2. Nilai budaya

Batik tulis motif kembang kopi ialah perpaduan antara kembang dan biji kopi yang mengahsilkan motif Kembang Kopi dengan menggunakan stilisasikan menjadi sebuah seni yang indah selain indah juga menghasilkan sebuah karya seni yang bermanfaat ialah sebagai penutup raga.

3. Nilai ekonomis

Pengrajin batik mendapat imbalan yang dapat digunakan untuk memenuhi kebutuhan hidupnya. Dimana keberadaan batik tulis di kampung Tanjung Bumi memberikan lapagan pekerjaan bagi para pengrajin untuk memenuhi banyaknya pesanan batik tulis dikarenakan sebagai bentuk eksistensi batik itu sendiri sehingga motif tidak tertinggal dengan motif-motif yang lainnya.

4. Nilai pendidikan dan filosofis

Upaya nilai pendidikan dan filosif khususnya pada batik tulis Tanjung Bumi dengan membawa batik tersebut ke sekolah baik dalam bentuk pelajaran intrakulikuler ataupun ekstrakulikuler. Dengan usaha tersebut agara generasi muda khususnya pelajar menjadi mengenal batik secara lebih mendalam. Pelajar juga diusahakan untuk bisa membuat batik tulis Tanjung Bumi supaya ikut melestarikan budaya batik yang berada di Tanjung Bumi, Bangkalan Madura Jawa Timur.

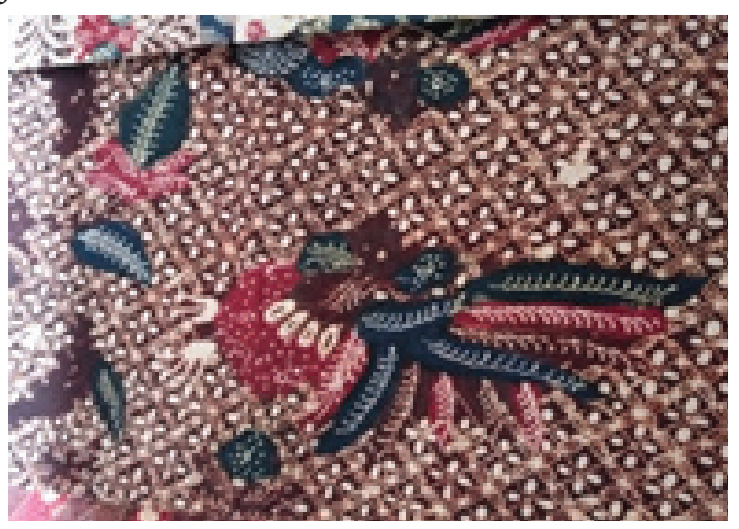

Gambar 6

Motif Kembang Kopi Tahun 2013

(Sumber : Suriyah di desa Macajah)

Ada beberapa Nilai-nilai yang terkandung dalam motif tersebut ialah : 
1. Nilai seni

Bervariasi, baik dari bahan, proses pembuatannya, maupun motifnya yang sekarang berkemban dengan pesat dan banyak diproduksi. Batik motif kembang kopi digunakan sebagai pakaian harian, pakaian resmi, dan pakaian seragam.

2. Nilai budaya

Batik tulis motif kembang kopi ialah perpaduan antara kembang dan biji kopi yang mengahsilkan motif kembang kopi dengan menggunakan stilisasikan menjadi sebuah seni yang indah selain indah juga menghasilkan sebuah karya seni yang bermanfaat ialah sebagai penutup raga.

3. Nilai ekonomis

Pengrajin batik mendapat imbalan yang dapat digunakan untuk memenuhi kebutuhan hidupnya. Dimana keberadaan batik di kampong tersebut memberikan lapagan pekerjaan bagi para pengrajin untuk memenuhi banyaknya pesanan pasar dikarenakan sebgai bentuk eksistensi batik itu sendiri sehingga motif tidak tertinggal dengan motif-motif yang lainnya.

4. Nilai pendidikan dan filosofis

Upaya nilai pendidikan dan filosif khususnya pada batik tulis Tanjung Bumi dengan membawa batik tersebut ke sekolah baik dalam bentuk pelajaran intrakulikuler ataupun ekstrakulikuler. Dengan usaha tersebut agara generasi muda khususnya pelajar menjadi mengenal batik secara lebih mendalam. Pelajar juga diusahakan untuk bisa membuat batik tulis Tanjung Bumi supaya ikut melestarikan budaya batik yang berada di Tanjung Bumi, Bangkalan Madura Jawa Timur

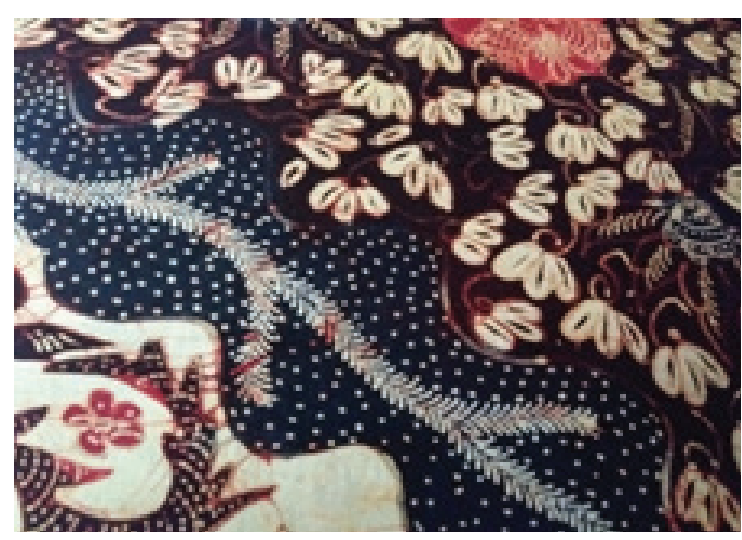

Gambar 7.

Motif Kembang Kopi Tahun 2015 (Sumber : Suriyah di desa Macajah)
Ada beberapa Nilai-nilai yang terkandung dalam motif tersebut ialah :

1. Nilai seni

Bervariasi, baik dari bahan, proses pembuatannya, maupun motifnya yang sekarang berkembang dengan pesat dan banyak diproduksi. Batik motif kembang kopi digunakan sebagai pakaian harian, pakaian resmi, dan pakaian seragam.

2. Nilai budaya

Batik tulis motif kembang kopi ialah perpaduan antara kembang dan biji kopi yang mengahsilkan motif kembang kopi dengan menggunakan stilisasikan menjadi sebuah seni yang indah selain indah juga menghasilkan sebuah karya seni yang bermanfaat ialah sebagai penutup raga.

3. Nilai ekonomis

Pengrajin batik mendapat imbalan yang dapat digunakan untuk memenuhi kebutuhan hidupnya. Dimana keberadaan batik di kampunng Tanjung Bumi memberikan lapagan pekerjaan bagi para pengrajin untuk memenuhi banyaknya pesanan pasar dikarenakan sebagai bentuk eksistensi batik tulis itu sendiri sehingga motif tidak tertinggal dengan motif-motif yang lainnya.

4. Nilai pendidikan dan filosofis

Upaya nilai pendidikan dan filosif khususnya pada batik tulis Tanjung Bumi dengan membawa batik tersebut ke sekolah baik dalam bentuk pelajaran intrakulikuler ataupun ekstrakulikuler. Dengan usaha tersebut agara generasi muda khususnya pelajar menjadi mengenal batik tulis secara lebih mendalam. Pelajar juga diusahakan untuk bisa membuat batik tulis Tanjung Bumi supaya ikut melestarikan budaya batik yang berada di Tanjung Bumi, Bangkalan Madura Jawa Timur.

Motif Kembang Kopi Batik tulis Tanjung Bumi ialah sangat beragam desainnya mulai dari sebelum 2005 itu sudah ada motif Kembang Kopi dan terus di kembangkan sampai 2015 ada 6 perkembangan dari situlah generasi muda patut untuk melesatrikan batik tersebut dikarenakan generasi patut mencotoh semanagat dan kreatifitas pengrajin di Tanjung Bumi Bangkalan Madura. 


\section{Kesimpulan Dan Saran}

Seni tradisi yang mempunyai bentuk dan aspek visual yang unik dan menarik bagi siapa saja yang melihat batikm akan terpesona oleh keindahan coretan motif-motif yang menghiasi kain yang ditorehkan dan ditata sedemikian rupa.

Kita sebagai generasi muda bangsa Indonesia di tuntut sadar untuk melestarikan, menjaga, mengembangkan, dan mempertahankan apa yang telah kita miliki sekaligus mengembangkannya, sehingga mampu bersaing dengan seni dan media-media modern, yang telah mengalihkan perhatian masyarakat dari seni budaya tradisional lokal bangsa indonesia sendiri.

Perkembangan batik tulis motif kembang kopi sangat berkembang pesat yang dulunya hanya memakai kembang dan biji kopi saja. Saat ini banyak perubahan dari kembang kopi yang dulunya hanya bermotif kembang dan sekarang dijadikan ekornya ayam dan tumbuhan lain yang mempuyai unsur keindahan pada kain batik tulis yang diciptakan oleh bu Suriyah.

\section{Daftar Pustaka}

\section{Buku}

Budiman, Kris. (2011). Semiotka visual. Yogyakarta, Jalasutra.

Idrus, Muhammad. (2009). Metode Penelitian Ilmu Sosial Pendekatan Kualitatif dan Kuantitatif Edisi Kedua. Yogyakarta: Universitas

Mifzal, Abiyu. (2012). Mengenal Ragam Batik Nusantara, Yogyakarta: Javalitera.

Wulan, Ari. (2011). Batik Nusantara. Yogyakarta: ANDI.

Tinarbuko, Sumbo. (2008). Semiotika Komunikasi Visual, Yogyakarta. Jalasutra.

\section{Daftar Internet}

Sumber: http:/4.bp.blogspot.com/ indonesialicenseplatesmap+ci. Png

Didownload pada hari minggu 14-08-2016 jam 12:13:30 WIB oleh penulis

Peta Pulau Madura : Sumber: http//ded3w. umm.ac.id/2010/0816/peta-Pulau-Madura. Didownload pada hari minggu 14-08-2016 jam 14:00 WIB oleh penulis.

\section{Jurnal}

Astrini, Andini Retno. (2018). Perancangan Video Profil Khasanah Batik "Adi Purwo" Kabupaten Purworejo.

Lestari, Septina Kurniasri. (2019). Pesona Kebaya Encim Modifikasi Dalam Sentuhan Motif Batik Mega Mendung. 